\title{
Degradation of Phospholipids by N, N-Dimethylformamide Induced Liver Toxicity in Male Wistar Rats
}

\author{
Jyothi Kanagaraj, Vasanthi Nachiappan, Ghurupreya Ramesh
}

\begin{abstract}
Dimethylformamide (DMF) is an industrially used solvent, prioritized by the National Toxicology Program as a potent hepatotoxic compound. The effect of DMF on liver is well documented; however its impact on hepatic phospholipids remains enigmatic. Hence, to understand the phospholipid metabolism we have developed an animal model for DMF induced hepatotoxicity. In the present study, DMF $(0.5,1.0,1.5 \mathrm{~g} / \mathrm{kg}$ body wt) was given intraperitoneally to male wistar rats and terminated after 24 and $48 \mathrm{~h}$. DMF with a concentration of $1.5 \mathrm{~g} / \mathrm{kg}$ body wt shows maximum toxic effect. Dosages higher than $1.5 \mathrm{~g} / \mathrm{kg}$ body wt showed lethal effect, hence in this study, $1.5 \mathrm{~g} / \mathrm{kg}$ body wt was used as maximum concentration. Induction of hepatotoxicity by $D M F$ was confirmed by liver marker enzymes. DMF impairs the liver phospholipid metabolism. DMF decreased the individual phospholipid levels by altering the fatty acid composition. There was an increase in unsaturated fatty acids with a concomitant decrease in saturated fatty acid. These changes in the fatty acid may directly or indirectly affect the membrane structure and fluidity. Understanding the mechanism by which DMF induced hepatotoxicity and alteration in phospholipid metabolism is a worthwhile pursuit.
\end{abstract}

Keywords-Fatty acid, Hepatotoxicity, Phospholipid, N, $N$-Dimethylformamide,

\section{INTRODUCTION}

N, N Dimethylformamide (DMF) is an organic solvent which is used worldwide in many industries such as textile industries, pharmaceutical industries, synthetic leather industries etc. DMF becomes an attractive industrial solvent because of its low volatility. Nowadays DMF utilization is contentious because of its harmful effects on exposure. DMF toxicity studies are being reported worldwide and still the count of liver damage cases are increasing in developing countries. Furthermore, several studies have been demonstrated to elucidate hepatotoxicity induced by DMF in human being as well as in animal models. The liver plays an essential role in the key functions of the organism. It is mainly susceptible to chemical injury due to its extensive metabolic capacity and cellular heterogeneity. The major target organ of DMF toxicity is the liver, due to its high content of

Revised Manuscript Received on December 15, 2019.

* Correspondence Author

Jyothi Kanagaraj*, Department of Biotechnology, Kalasalingam Academy of Research and Education, Krishnankoil..Email: jyothi.k@klu.ac.in

Vasanthi Nachiappan, Department of Biochemistry, Bharathidasan University. Tiruchirappalli. Email: vasanthinr@gmail.com

Ghurupreya Ramesh, Department of Biotechnology, Kalasalingam Academy of Research and Education, Krishnankoil. Email: ghurupreyalakshmi5@gmail.com cytochrome P-450 [1] DMF metabolism takes place in the liver, and excreted as metabolites through urine (Hantson et al., 2010). Previous studies have revealed that DMF is $\mathrm{N}$-methylated by the liver microsomal enzymes, and cytochrome P-450 involves in the biotransformation [2]. Thus, DMF toxicity is more severe in the liver cells compared to any other organ, probably because DMF metabolism is mainly catalyzed by cytochrome P450 [3]. Biological membranes are more susceptible to environmental toxicants. DMF, a lipid-soluble organic solvent, may penetrate the biological membrane, thus disturbs the properties of membrane. Interactions of DMF with cell membrane rely on lipid bilayer constituents and molecules inserted within the membrane. Phospholipids, the major constituents of biological membranes, involves in various metabolic functions like maintaining the cellular permeability, regulating the membrane proteins and regulating the intracellular signaling etc. [4].The lipid peroxidation in membrane phospholipids are enhanced by DMF due to the production of reactive oxygen species (ROS), and was also reported [5]. Earlier reports focused mainly on the impact of DMF on liver toxicity and there is paucity of information on phospholipid metabolism. The compound chosen for this study, DMF, interact directly with the components of membrane; hence we aimed to examine the effect of acute toxicity of DMF on phospholipid metabolism.

\section{MATERIALS AND METHODS}

\section{A. Chemicals}

N, N-Dimethylformamide (purity greater than 99\%) purchased from Merck Specialties Private Ltd., Mumbai, India. BF3-methanol, heptadecanoic methyl ester (C17), TRIzol, bovine serum albumin (BSA) and EDTA (Sigma Aldrich). Silica Gel TLC plates (60F254) were purchased from Merck. All chemicals and solvents, used in this work, unless specifically mentioned, were purchased from Sigma..

\section{B. Animals}

Male albino rats (Wistar strain) weighing 150-200 g were obtained from Central Animal facility, IISC Bangalore, India. The animals were caged in animal house, Bharathidasan University, Trichy, India, under hygienic and normal environmental conditions (temperature: $24 \pm 1^{\circ} \mathrm{C}$, light/dark cycle: $12 / 12 \mathrm{~h}$ ). The animals were given standard pellet diet and water ad libitum. The rats were used for experiment after obtaining prior permission from Bharathidasan University and Institutional legislation as regulated by the CPCSEA 
(Committee for the Purpose of Control and Supervision of Experiments on Animals), Ministry of Social Justice and Empowerment, Government of India.

The rats were injected with various concentrations of DMF, $0.5,1.0,1.5 \mathrm{~g} / \mathrm{kg}$ body wt for various time intervals (24 $\& 48 \mathrm{~h}$ ) and $1.5 \mathrm{~g} / \mathrm{kg}$ body wt was the maximum toxic effect observed. Dosages higher than $1.5 \mathrm{~g} / \mathrm{kg}$ body wt showed lethal effect, hence $1.5 \mathrm{~g} / \mathrm{kg}$ body wt was the concentration used in this studies. The animals were separated into seven groups of 6 animals each. The control group was given saline (intraperitoneally) and terminated after $48 \mathrm{~h}$. The other groups were intraperitoneally injected with DMF, $0.5 \mathrm{~g} / \mathrm{kg}$ b.wt for $24 \& 48 \mathrm{~h}$ (Group II \& III), $1.0 \mathrm{~g} / \mathrm{kg}$ b.wt for $24 \& 48$ h (Group IV \& V) and $1.5 \mathrm{~g} / \mathrm{kg}$ b.wt for $24 \& 48 \mathrm{~h}$ (Group VI \& VII), as described by Roure et al [6] and terminated by cervical dislocation under anaesthesia (ketamine $50 \mathrm{mg} / \mathrm{kg}$ b.wt). The blood was collected in tubes with/without (anti coagulant) potassium EDTA. Liver was dissected out quickly and washed with saline (ice- cold). The liver samples were stored at $-20^{\circ} \mathrm{C}$.

\section{Biochemical Analysis}

Blood samples from both control and DMF- treated rats were collected and centrifuged at $2000 \mathrm{rpm}$ for 5 minutes at $4^{0} \mathrm{c}$. The serum samples were separated and assayed within $24 \mathrm{~h}$ by using standard laboratory techniques based on manufacturer's protocol. Liver function tests like SGOT, SGPT, $\gamma$ GT and ALP were assayed using standard kits from Euro diagnostics, Chennai.

\section{Lipid extraction and seperationn by Thin layer chromatography}

The total lipids were extracted from liver samples followed by Folch et al., [7] method. In brief, to I $g$ of the tissue homogenate $10 \mathrm{ml}$ of 2:1 ratio of chloroform and methanol were added and vortexed. $5 \mathrm{ml}$ of $2 \%$ orthophosphoric acid was added and vortexed vigorously. Then it was subjected to centrifugation at $10,000 \mathrm{rpm}$ for 2 min. The lower phase was collected and dried under speed vacuum concentrater. The dried mass were dissolved in minimal volume of chloroform: methanol $(2: 1 \mathrm{v} / \mathrm{v})$ and stored at $-20^{\circ} \mathrm{C}$. Total lipids were isolated using $2-\mathrm{D}$ TLC with silica gel. The phospholipids in the TLC plates were separated by using the solvent systems, chloroform, methanol and ammonia $(70: 30: 5 \mathrm{v} / \mathrm{v})$ for first dimension and chloroform, methanol and water $(65: 35: 5 \mathrm{v} / \mathrm{v})$ for second dimension. Seperated spots of lipids were identified by measuring the $R f$ values of the unknown sample to that of the $R f$ values of the standard. Phospholipids were visualized under brief exposure to iodine vapours

\section{E. Phospholipid determination by Phosphorus assay}

The separated phospholipids, by TLC, were quantified by Rouser et al., [8] method. The scraped spots from the TLC, were treated with $70 \%$ perchloric acid at $180^{\circ} \mathrm{C}$ for $1 \mathrm{~h}$. After incbation, $3.3 \mathrm{ml}$ of distilled water, $2.5 \%$ ammonium molybdate $(0.5 \mathrm{ml})$, and $10 \%$ ascorbic acid $(0.5 \mathrm{ml})$ were added and kept in a boiling water bath for 5 minutes. Similarly standards were also prepared and digestion was not required. The samples were kept at room temperature and absorbance was read at $800 \mathrm{~nm}$. Classically $5 \mu \mathrm{g}$ standard gave an absorbance of 0.9 . The quantity of phospholipid was

calculated directly on molar basis (phosphorus) and weight basis by multiplying the quantity of phosphorus by 25 .

\section{F. Fattyacid analysis}

Phospholipids extracted from the liver of control and DMF-treated animals were subjected for fatty acids analysis by Gas chromatography-mass spectrometry (GC/MS). From the total lipids the individual lipids were separated and extracted from the TLC plate silica gel with chloroform and methanol $(2: 1 \mathrm{v} / \mathrm{v})$, and subjected to methanolysis using $\mathrm{BF} 3 /$ methanol for conversion to methyl esters [9]. The methyl esters of fatty acid were separated by GC/MS and quantified using an internal standard heptadecanoic methyl ester (C17).

\section{G. Data analysis}

Data was analyzed using ANOVA and (LSD) least significant difference, post-hoc test to compare individual means. The results were expressed as mean \pm SD of at least two independent experiments. A difference of $\mathrm{p}<0.05$, $\mathrm{p}<0.01$ and $\mathrm{p}<0.001$ was considered to be statistically significant.

\section{RESULT AND DISCUSSION}

Earlier evidences focused mainly on the impact of DMF on liver toxicity and there is an inadequate of information of phospholipid metabolism. In our laboratory, we have shown that DMF directly interacts with the biological membrane and thus alters the lipid metabolism. We investigated the effect of DMF on phospholipid metabolism in liver using rat as a model system.

\section{A. DMF exposure increases the serum marker enzymes}

To determine the effect of DMF on liver marker enzymes like SGOT, SGPT, ALP, $\gamma-$ GT and SDH were analyzed in both control and DMF treated rats. Different doses of DMF significantly increased $(p<0.001)$ all the liver enzymatic markers (indicative of liver injury) at both 24 and $48 \mathrm{~h}$ comparing to its control (Table 1) and the effect was maximum at $1.5 \mathrm{~g} / \mathrm{kg}$ body wt of DMF administration after 48 h.

TABLE -I: Effect of DMF on the activities of liver marker enzymes in serum

\begin{tabular}{|c|c|c|c|c|c|c|}
\hline \multicolumn{2}{|c|}{$\begin{array}{l}\text { Parameter } \\
\text { s }\end{array}$} & SGOT & SGPT & YGT & SDH & ALP \\
\hline \multicolumn{2}{|c|}{ Units } & $(\boldsymbol{U} / L)$ & $(\boldsymbol{U} / L)$ & $(\boldsymbol{U} / L)$ & $(U / L)$ & (Ka Units) \\
\hline \multicolumn{2}{|c|}{ Control } & $210 \pm 5.10$ & $\begin{array}{l}115 \pm \\
4.23\end{array}$ & $\begin{array}{l}40 \pm \\
2.57\end{array}$ & $\begin{array}{l}204 \pm \\
3.24\end{array}$ & $10 \pm 0.81$ \\
\hline \multirow{2}{*}{ 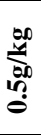 } & $24 \mathrm{~h}$ & $256 \pm .23^{*}$ & $\begin{array}{l}160 \pm \\
4.21^{*}\end{array}$ & $\begin{array}{l}98 \pm \\
2.46^{*}\end{array}$ & $\begin{array}{l}220 \pm \\
2.62 *\end{array}$ & $14.7 \pm 1.01^{*}$ \\
\hline & $48 \mathrm{~h}$ & $258 \pm .51 *$ & $\begin{array}{l}180 \pm \\
4.25^{*}\end{array}$ & $\begin{array}{l}106 \pm \\
2.22^{*}\end{array}$ & $\begin{array}{l}226 \pm \\
3.48^{*}\end{array}$ & $17.8 \pm 1.05^{*}$ \\
\hline \multirow{2}{*}{ 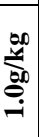 } & $24 \mathrm{~h}$ & $272 \pm .46^{*}$ & $\begin{array}{l}200 \pm \\
4.28^{*}\end{array}$ & $\begin{array}{l}140 \pm \\
2.27^{*}\end{array}$ & $\begin{array}{l}248 \pm \\
3.53^{*}\end{array}$ & $18.2 \pm 1.15^{*}$ \\
\hline & $48 \mathrm{~h}$ & $275 \pm 4.35$ & $\begin{array}{l}208 \pm \\
4.26^{*}\end{array}$ & $\begin{array}{l}148 \pm \\
2.23^{*}\end{array}$ & $\begin{array}{l}252 \pm \\
3.59 *\end{array}$ & $20.8 \pm 1.20 *$ \\
\hline \multirow{2}{*}{ 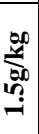 } & $24 \mathrm{~h}$ & $310 \pm .29 *$ & $\begin{array}{l}255 \pm \\
4.20 *\end{array}$ & $\begin{array}{l}170 \pm \\
2.20^{*}\end{array}$ & $\begin{array}{l}280 \pm \\
3.65^{*}\end{array}$ & $26.5 \pm 1.34^{*}$ \\
\hline & $48 \mathrm{~h}$ & $318 \pm .34 *$ & $\begin{array}{l}262 \pm \\
4.21^{*}\end{array}$ & $\begin{array}{l}178 \pm \\
2.20^{*}\end{array}$ & $\begin{array}{l}286 \pm \\
3.69^{*}\end{array}$ & $29.5 \pm 1.42 *$ \\
\hline
\end{tabular}

DMF affect the liver cell metabolism which reflects in the serum liver marker enzymes activities [10]. 
SGOT, SGPT, rGT and ALP are the sensitive liver marker enzymes, located in the cytoplasm. Any hepatic cellular disturbance leads to the release of these enzymes in circulation [11].

\section{B. Impact of DMF on liver phospholipids}

Fig. 1 depicted the quantification of liver individual phospholipids during DMF (1.5 g/ kg b.wt.) induced hepatotoxicity in rats at $24 \& 48 \mathrm{~h}$. Rats showed significant reduction in major liver phospholipids at both the time intervals compared to its control. Significant reduction in PC $(\sim 41 \%)$, PE $(\sim 15 \%)$, PI $(\sim 30 \%)$ PA $(\sim 40 \%)$ and significant elevated level of PS $(\sim 48 \%)$ and LPC $(\sim 50 \%)$ were observed during $1.5 \mathrm{~g} / \mathrm{kg}$ b.wt treatment (Fig. $6 \mathrm{C}$ ). In the present study, phospholipid metabolism was altered in liver which was fully supported with our experimental evidences using rat as a model system. To understand the effect of DMF on phospholipid metabolism, the rats were injected with a broad range of DMF. We observed reduction in phospholipids, particularly PC and PA with a concomitant increased in LPC at a concentration of $1.5 \mathrm{~g} / \mathrm{kg}$ b.wt (figure $6 \mathrm{C}$ ). Not much alteration was observed in PE and PI.

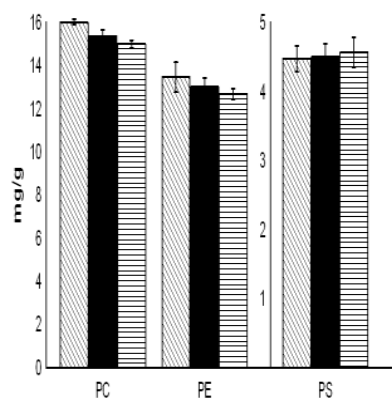

Fig. IA

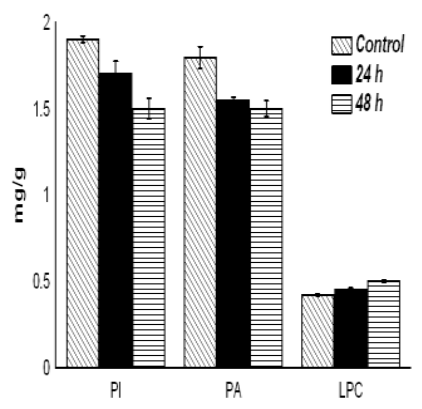

$*$ represents significance at $<0.001$ level.

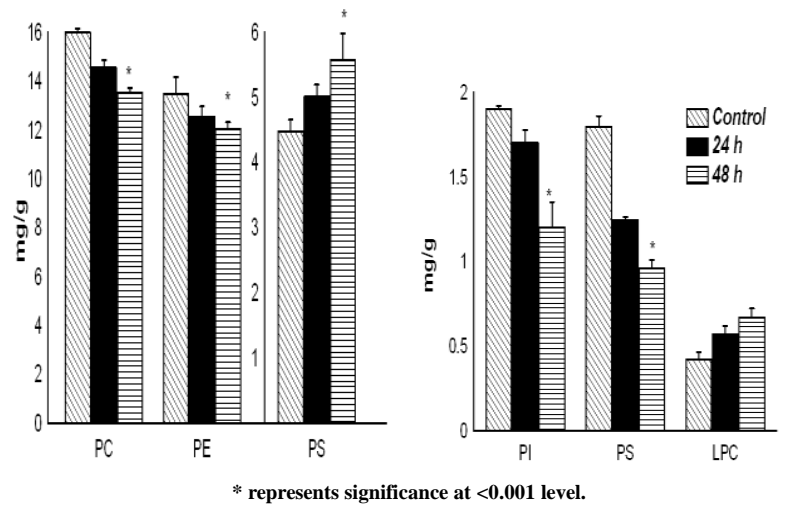

Fig. IB

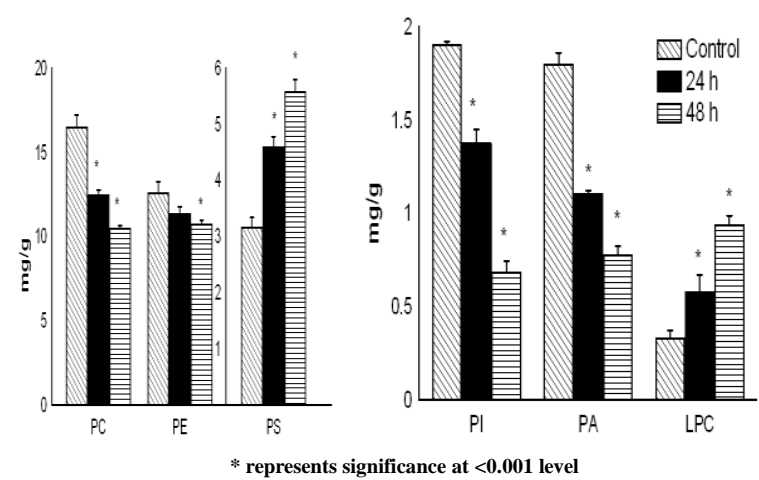

Fig. 1C
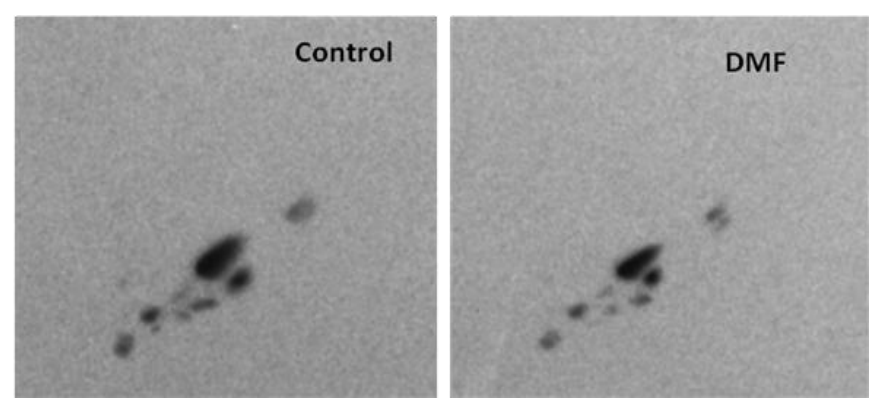

Fig. IC.1

Figure.1---Impact of DMF on liver phospholipid metabolism

Animals were treated with $\operatorname{DMF}(0.5,1.0 \& 1.5 \mathrm{~g} / \mathrm{kg} \mathrm{b.wt})$ and euthanized after $24 \mathrm{~h}$ and $48 \mathrm{~h}$. From the liver, lipids were extracted and determined on 2D TLC. The spots were visualized by iodine. The individual phospholipids were scraped off and the amount of PL was measured by phosphorus assay $1.5 \mathrm{~g} / \mathrm{kg}$ b.wt. DMF treated rats showed a significant reduction in liver phospholipids at both the time intervals when compared to its control. The corresponding chromatogram of $0.5 \mathrm{~g} / \mathrm{kg}$ (IA), $1.0 \mathrm{~g} / \mathrm{kg}$ (IB) and $1.5 \mathrm{~g} / \mathrm{kg}$ (IC), was represented as $\mathrm{mg} / \mathrm{g}$ of tissue. 2-D TLC shows a significant decrease in PL content at $1.5 \mathrm{~g} / \mathrm{kg}$ b.wt of DMF (IC.1) •

\section{Fatty acid analysis of liver phospholipids}

We elucidated the acyl chain alteration in total liver phospholipid by GC-MS. A change in acyl chain composition of phospholipids (Table 2) was observed in DMF induced rat liver. Fatty acids in PL were converted to fatty acid methyl esters and subjected to GC/MS. Using an internal standard, heptadecanoic methyl ester, the fatty acids were quantified. The data represented here is the mean of three independent experiments \pm SD. Exposure of DMF to rat, showed an overall decline in saturated fatty acids (C16:0, C18:0, C20:0, C22:0) and a rise in unsaturated fatty acids (16:1, 18:1, 18:2, 20:4, 22:4, 22:6). Particularly, DMF decreases the levels of long chain fatty acids (C16:0, C18:0, C20:0) and subsequently increases unsaturated fatty acids (C16:1, C18:1, C20:4).

\section{Fatty acid analysis of liver individual phospholipids upon DMF induction}

The fatty acid molecular species analysis was carried out in major phospholipid PC and also analyzed its degradation product LPC. Table $3 \mathrm{~A}$ depicts the altered acyl chain of $\mathrm{PC}$ in DMF induced rat liver. PC showed a significant $(p<0.001)$ decrease in saturated fatty acid (C16:0, C18:0, C20:0, C22:0) content with concomitant increase in unsaturation (16:1, 18:1, 18:2, 20:4, 22:4, 22:6). In LPC (Table 3B) a significant reduction was observed only in $\mathrm{C} 20: 0$ and $\mathrm{C} 24: 0$. The short chain fatty acid, C12:0, was increased significantly in LPC with an elevation of C16:1, C18:1 and C18:2.

The fatty acid composition was investigated by gas chromatography and mass spectrophotometric (GC/MS) analysis of phospholipid molecular species in DMF induced hepatotoxicity. 
TABLE-2: Percentage composition of fatty acid molecular species in liver phospholipid from rats subjected to DMF

\begin{tabular}{|l|l|l|l|}
\hline Fattyacid \% & Control & DMF(24h) & DMF(48h) \\
\hline C 16:0 & $15.08 \pm 1.03$ & $12.66 \pm 0.58^{*}$ & $11.52 \pm 0.89^{*}$ \\
\hline C18:0 & $14.54 \pm 1.08$ & $12.6 \pm 0.49^{*}$ & $11.94 \pm 0.63^{*}$ \\
\hline C20:0 & $8.57 \pm 0.8$ & $6.34 \pm 1.0^{*}$ & $6.5 \pm 1.0 *$ \\
\hline C22:0 & $5.88 \pm 0.5$ & $3.5 \pm 0.5^{*}$ & $3.01 \pm 0.5^{*}$ \\
\hline C16:1 & $12.56 \pm 0.5$ & $14.7 \pm 0.5^{*}$ & $14.5 \pm 0.5^{*}$ \\
\hline C18:1 & $13 \pm 0.8$ & $14.78 \pm 0.8^{*}$ & $15.87 \pm 0.7 *$ \\
\hline C18:2 & $12.85 \pm 0.84$ & $14.24 \pm 0.23^{*}$ & $14.32 \pm 1.23^{*}$ \\
\hline C20:4 & $15.08 \pm 0.5$ & $17.18 \pm 0.51^{*}$ & $17.44 \pm 0.77^{*}$ \\
\hline C22:4 & $2.44 \pm 0.43$ & $4.0 \pm 0.13^{*}$ & $4.9 \pm 1.03^{*}$ \\
\hline SFA & 44.07 & 35.1 & 32.97 \\
\hline UFA & 55.93 & 64.9 & 67.03 \\
\hline SFA/UFA & 0.787 & 0.54 & 0.491 \\
\hline MUFA/PUFA & 0.841 & 0.832 & 0.828 \\
\hline & & $*$ represents significance at p $<0.001$ \\
\hline
\end{tabular}

The exposure of DMF significantly alters the fatty acid composition in both total and individual phospholipids.

The maximum alteration was observed in PC, the palmitic acid (C16:0) and stearic acid (C18:0) were significantly reduced with significant increase of $(\mathrm{C} 16: 1)$ palmitoleic and (C18:1) oleic acid. Arachidonic acid (C20:4) was significantly increased (29-33\%) by DMF exposure.

\section{TABLE 3A: Percentage composition of fatty acid molecular} species in $\mathbf{P C}$

\begin{tabular}{|c|c|c|c|}
\hline Fatty acid \% & Control & DMF(24h) & DMF(48h) \\
\hline C14:0 & $5.35 \pm 0.52$ & $4.2 \pm 0.45^{*}$ & $3.12 \pm 0.57 *$ \\
\hline C16:0 & $\begin{array}{l}23.27 \pm 5.2 \\
6\end{array}$ & $\begin{array}{l}18.19 \pm 4.78 \\
*\end{array}$ & $\begin{array}{l}16.34 \pm 4.48 \\
*\end{array}$ \\
\hline C18:0 & $\begin{array}{l}16.01 \pm 3.2 \\
4\end{array}$ & $\begin{array}{l}12.34 \pm 3.56 \\
*\end{array}$ & $\begin{array}{l}12.12 \pm 4.32 \\
*\end{array}$ \\
\hline C20:0 & $6.85 \pm 1.23$ & $4.5 \pm 0.84 *$ & $4.21 \pm 0.74 *$ \\
\hline $\mathrm{C} 24: 0$ & $0.81 \pm 0.05$ & $0.42 \pm 0.03 *$ & $\begin{array}{l}0.42 \pm 0.045 \\
*\end{array}$ \\
\hline C16:1 & $\begin{array}{l}10.87 \pm 1.2 \\
7\end{array}$ & $\begin{array}{l}12.01 \pm 2.54 \\
*\end{array}$ & $\begin{array}{l}13.15 \pm 2.51 \\
*\end{array}$ \\
\hline C18:1 & $9.02 \pm 1.2$ & $12.3 \pm 2.98^{*}$ & $\begin{array}{l}12.01 \pm 3.26 \\
*\end{array}$ \\
\hline $\mathrm{C} 18: 2$ & $13.05 \pm 3.4$ & $\begin{array}{l}16.43 \pm 3.78 \\
*\end{array}$ & $\begin{array}{l}17.09 \pm 4.21 \\
*\end{array}$ \\
\hline C20:4 & $11.2 \pm 2.87$ & $\begin{array}{l}14.54 \pm 3.42 \\
*\end{array}$ & $15.00 \pm 4.7 *$ \\
\hline $\mathrm{C} 22: 6$ & $3.57 \pm 0.54$ & $5.07 \pm 1.23 *$ & $6.54 \pm 0.9^{*}$ \\
\hline SFA & 52.29 & 39.65 & 36.21 \\
\hline UFA & 47.71 & 60.35 & 63.79 \\
\hline SFA/UFA & 1.09 & 0.65 & 0.56 \\
\hline MUFA/PUFA & 0.71 & 0.67 & 0.65 \\
\hline
\end{tabular}
DMF treated rat liver. inflammatory process. BDU.

\begin{tabular}{|l|l|l|l|}
\hline $\begin{array}{l}\text { Fatty acid } \\
\text { \% }\end{array}$ & Control & DMF(24h) & DMF(48h) \\
\hline C12:0 & $2.46 \pm 0.52$ & $4.72 \pm 0.45^{*}$ & $\begin{array}{l}5.13 \pm 0.57 \\
*\end{array}$ \\
\hline C14:0 & $9.11 \pm 5.26$ & $8.66 \pm 4.78$ & $8.91 \pm 4.48$ \\
\hline C16:0 & $50.24 \pm 3.24$ & $\begin{array}{l}46.02 \pm 3.56 \\
*\end{array}$ & $\begin{array}{l}46.0 \pm 4.32 \\
*\end{array}$ \\
\hline C18:0 & $31.95 \pm 3.24$ & $31.39 \pm 3.56$ & $\begin{array}{l}30.27 \pm 4.3 \\
2\end{array}$ \\
\hline C20:0 & $0.49 \pm 1.23$ & $0.23 \pm 0.84 *$ & $\begin{array}{l}0.21 \pm 0.74 \\
*\end{array}$ \\
\hline C24:0 & $0.37 \pm 0.05$ & $0.11 \pm 0.14^{*}$ & $\begin{array}{l}0.1 \pm 0.045 \\
*\end{array}$ \\
\hline C16:1 & $1.63 \pm 1.27$ & $3.18 \pm 2.54 *$ & $\begin{array}{l}3.51 \pm 2.51 \\
*\end{array}$ \\
\hline C18:1 & $3.75 \pm 1.2$ & $5.69 \pm 2.98^{*}$ & $\begin{array}{l}5.87 \pm 3.26 \\
*\end{array}$ \\
\hline SFA & 94.62 & 91.13 & 90.62 \\
\hline UFA & 5.38 & 8.87 & 9.38 \\
\hline SFA/UFA & 17.58 & 10.27 & 9.66 \\
\hline
\end{tabular}

These results obviously showed the fall in phospholipid, accompanied with simultaneous increase in lyso-phospholipid. The fatty acid molecular species was also altered in PC by DMF. The reduction of phospholipids might be due to hydrolysis of phospholipids by activated phospholipase with respect to DMF exposure.

Our results revealed that DMF significantly diminishes the liver phospholipids by enhancing deacylation process accompanied with drastic change in the composition of fattyacid in major liver PC. The acyl-chain composition of phospholipids is essentially determined by deacylation-reacylation cycle (Lands. 1958). Our fatty acid analysis reveals decreased palmitic acid content was compensated by increased arachidonic acid content in PC of

\section{CONCLUSION}

The present study is the first information on the effect of $\mathrm{N}$, N-Dimethylformamide (DMF) on liver phospholipid metabolism using rat as model system. DMF mediated hepatotoxicity is very well documented. However its impact on lipid metabolism remains enigmatic. DMF primarily targets the liver and most of the integral lipids and lipoproteins are synthesized in the liver. Hence the present study was undertaken to explore the impact of DMF on phospholipid metabolism. The phospholipids were reduced significantly in liver with altered fatty acid compositions with increased arachidonic acid that plays a key role in

\section{ACKNOWLEDGMENT}

The authors would like to thank the Department of Biotechnology, KARE and Department of Biochemistry, 


\section{REFERENCES}

1. V. Scailteur and R. R. Lauwerys, "Dimethyl formamide hepatotoxicity," Toxicol, vol.43, pp 231-238,1987.

2. P. Hantson et al, "Dimethylformamide metabolism following self-harm using a veterinary euthanasia product," Clin Toxicol (Phila), vol. 48 pp. 725, 2010.

3. G. Amato, E. Grasso , V. Longo , P.G. Gervasi ,(2001) "Oxidation of $\mathrm{N}, \mathrm{N}$-dimethylformamide by human liver microsomes and human recombinant P450s", Toxicol. Lett, vol.124pp.11-9,2001.

4. J.H. Exton (1994) "Phosphatidylcholine breakdown and signal transduction,” Biochim. Biophys. Acta, vol. 1212pp.26-42,1994.

5. K. Jyothi, D. Kalyani and N.Vasanthi, "Effect of acute exposure of N, $\mathrm{N}$-Dimethylformamide, an industrial solvent on lipid peroxidation and antioxidants in liver and kidney of rats,". Indian. Journal. Biochem. Biophysics, vol. 49pp. 279-84, 2012.

6. M. B. Roure, A. M. Lambert, C. Cour, P. Bonnet and A.M. Saillenfait, "Hepatotoxicity of N, N-Dimethylformamide in rats following intraperitoneal or inhalation routes of administration," J. Appl. Toxicol.vol, 16 pp. $265-7,1996$.

7. J. Folch, M. Lees and G. H. Sloane-Stanley, "A simple method for the isolation and purification of total lipids from animal tissues," J. Biol. Chem, vol. 226 pp. 497-509, 1957.

8. G. Rouser, S. Fleischer and Yamamoto, "Two dimensional thin layer chromatography separation of polar lipid and determination of phospholipids by phosphorous analysis of spots," Lipid, vol. 5, pp. 494-496, 1970

9. W. R. Morrison and L. M. Smith, "Preparation of fatty acid methyl esters and dimethylacetals from lipids with boron fluoridemethanol," J. Lipid Res, vol.5, pp. 600-608, 1964.

10. S. K. Mitra, M. V. Venkataranganna, R. Sundaram, and S. Gopumadhavan, "Protective effect of HD-03, a herbal formulation, against various hepatotoxic agents in rats,"J Ethano Pharmacol, vol. 63, pp. 181-186, 1998.

11. R. Sallie, J. M. Tredger, and R. Willam, "Drugs and the liver," Biopharm. Drug. Dispos, vol. 12, pp. 251-259.1991.

12. Lands W E, "Metabolism of glycerolipides; a comparison of lecithin and triglyceride synthesis," J. Biol. Chem, vol. 23, pp. $883-888,1958$ 